\title{
A useful and simple tool to evaluate and compare the intake of total dietary polyphenols in different populations
}

\author{
Daniel Hinojosa-Nogueira ${ }^{1}$, Sergio Pérez-Burillo ${ }^{1}$, Inés García-Rincón ${ }^{1}$, \\ José A Rufián-Henares ${ }^{1,2, *}$ (i) and Silvia Pastoriza ${ }^{1}$ \\ 'Departamento de Nutrición y Bromatología, Instituto de Nutrición y Tecnología de los Alimentos, Centro de \\ Investigación Biomédica, Universidad de Granada, Granada, Spain: ${ }^{2}$ Instituto de Investigación Biosanitaria \\ IBS.Granada, Universidad de Granada, Granada, Spain
}

Submitted 16 October 2020: Final revision received 7 April 2021: Accepted 22 April 2021: First published online 27 April 2021

\begin{abstract}
Objective: Polyphenols are antioxidant compounds with an impact on different health factors. Thus, it is important to have precise tools to estimate the intake of polyphenols. This study focuses on the development of an intuitive tool to estimating the intake of dietary total polyphenols.

Design: The tool was developed in a spreadsheet to improve accessibility and use. It is divided into six different meals for each of the $7 \mathrm{~d}$ with a similar format to $24-\mathrm{h}$ diet recalls. The total polyphenol values of 302 foods were included and the possibility of own values.

Setting: Framework of the European project Stance4Health, Granada, Spain.

Participants: This tool was tested on 90 participants in different stages of life (girls, women and pregnant women). Ages ranged from 10 to 35 years.

Results: The total polyphenol intake obtained was of $1790 \pm 629 \mathrm{mg}$ polyphenols/

$\mathrm{d}$. The highest consumption of polyphenols was observed in pregnant women (2064 mg/d). Polyphenols intake during the weekend was lower for the three groups compared to the days of the week. The results were comparable with those of other studies.

Conclusions: The current tool allows the estimation of the total intake of polyphenols in the diet in a fast and easy way. The tool will be used as a basis for a future mobile application.
\end{abstract}

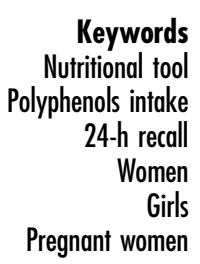

Currently, epidemiological studies recognise the influence of diet on the risk of different diseases such as CVD, diabetes, obesity or cancer $^{(1)}$. As an example, it has been proven that different eating patterns such as the Mediterranean $\operatorname{diet}^{(2)}$ include the intake of high levels of specific compounds like polyphenols ${ }^{(3)}$, which in turn are associated with different beneficial effects ${ }^{(4)}$. Polyphenols are a heterogeneous group of plant secondary metabolites with more than 8000 different compounds described, and many of them are associated with health benefits ${ }^{(5)}$. Phenolic compounds are divided into several subclasses: anthocyanins, flavanols, flavonones, flavones, flavonols, hydroxybenzoic acids, hydroxycinnamic acids, isoflavones, lignans, proanthocyanidins and stilbenes $^{(6)}$.
Consequently, it is clear the importance of being able to calculate the amount of these compounds that are regularly ingested with the diet. The first step for the estimation of polyphenol intake is the use of a reliable method for food intake evaluation, such as $24-\mathrm{h}$ diet recalls (24hR) or FFQ ${ }^{(7)}$. The $24 \mathrm{hR}$ provide more detailed information than $\mathrm{FFQ}^{(8)}$; however, $24 \mathrm{~h}$ have some problems: (a) in order to be the representative of the usual intake, the information must be collected over several days; and (b) they are also more uncomfortable and take longer to fill than $\mathrm{FFQ}^{(9)}$. On the other hand, FFQ are usually the methodology of choice since they are cheaper and easier to apply ${ }^{(10-12)}$. However, they are based on a fixed list of foods in which there is usually some items missing, more often than not 
they are commonly consumed products, and really important for polyphenol intake as in the case of spices.

Regardless of the methodology, once the dietary data have been collected, they should be transformed into polyphenol intake. Although there are several food databases available providing food phenolic content, in most investigations two are usually used: the United States Department of Agriculture (USDA) database ${ }^{(13)}$ and Phenol-Explorer ${ }^{(14,15)}$. However, USDA database only has the values of flavonoids. Phenol-Explorer, on the other hand, has values for total polyphenol content as well as for each of the phenolic compounds and subclasses. Moreover, it also provides with information about retention factors for cooked or processed foods ${ }^{(14-16)}$. Nowadays, Phenol-Explorer is the most complete and most widely used database in European countries ${ }^{(7,9)}$.

There is not a consensus about the methodology to gather dietary information, some studies use FFQ and others 24hR; using different food composition databases also produces inconsistent results along studies. In addition, there is not a protocol to calculate phenolic intake that states which data use as input (total phenolic content $v$. the sum of all phenolic subclasses available $)^{(7)}$. All these issues lead to a significant disagreement when it comes to calculate phenolic intake of a certain population, usually oscillating between 1 and $3 \mathrm{~g} / \mathrm{d}^{(17,18)}$. These variations could be overcome if a standardised protocol existed. Therefore, the aim of the present manuscript is to describe an intuitive and user-friendly tool to facilitate the calculation of polyphenol intake that will be released as a spreadsheet freely available for other researchers in the field. This tool is the prototype on which a mobile application under development will be based, which will calculate in addition to the total intake of polyphenols, the intake of individual polyphenols, classes and subclasses.

\section{Materials and methods}

\section{Tool development}

The tool was created in a Microsoft Excel $2007{ }^{\circledR}$ spreadsheet (Redmond, USA), which is attached as supplementary material (S1). The .xls format was chosen because most users find it accessible and easy to use. This format allows it to be used by different versions of Microsoft Excel or by other softwares such as Apache OpenOffice ${ }^{\circledR}$. It was developed in two languages, Spanish and English (only the English version is attached as supplementary material, but the Spanish version can be sent upon request). The tool consists of twelve different spreadsheets and is password protected, to prevent formulas from being modified by mistake, which could generate calculation errors.

The first spreadsheet contains a description of the tool and the bibliography used ${ }^{(14-16)}$. Next seven spreadsheets represent each day of the week, with the possibility to choose among all the available foods. The daily intake is divided into six different meals: breakfast, mid-morning snack, lunch, mid-afternoon snack, dinner and a wild card for 'in between hours' intakes. Within each meal, up to eighteen different food items can be added. Additionally, there are two empty slots (marked in green), in case the subject wants to enter values of any specific foodstuff, such as recipes, supplements or other that are not included in the tool. In order to obtain the phenolic intake, the user only has to select the consumed food and the ingested amount. The tool will show total polyphenol intake provided by the specific food, by the complete meal, per day, and per group of food. Spreadsheets 10 to 12 collect all the values, calculating the means and the standard deviations of the total polyphenol intake by week, and by weekdays or weekends, always arranged by food groups. Finally, the last spreadsheet is an open table so that up to thirty-two participants can be entered allowing to calculate the weekly average intake of a population, giving also the possibility of classifying participants by gender.

\section{Foods included in the tool}

Total polyphenol content of 302 foods was recorded. These values were extracted from the Phenol-Explorer database. The goal was to have as many foods as possible. Therefore, foods that had total polyphenol values were added and the tool was complemented with sixty additional food items without total polyphenol value. Their total phenolic content value was obtained by summing the different polyphenol families provided by the Phenol-Explorer database. The retention factors of most foods have not been taken into account, only in specific cases (such as boiled rice or potato chips) where information was verified. Foods were classified into sixteen groups: oils and olives (9), juices (13), alcoholic drinks (15), coffee, cocoa and derivatives (8), cereals and derivatives (23), condiments (20), fruits and derivatives (70), nuts (16), herbs (18), infusions (10), legumes (13), soya and derivatives (14), tubers (4), vegetables (56), processed foods (12), and others (1). All the foods corresponding to these groups are detailed in the tool. The group called 'others' is an empty slot that allows the user to enter additional items. Moreover, twelve foods that were classified as 'processed' were added. These foods were introduced since they are commonly consumed by the Spanish population ${ }^{(10,19)}$. Table 1 shows the foods that have been classified as processed, as well as their ingredients. Only those ingredients that contribute to the phenolic intake have been shown. The recipes have been elaborated following a Mediterranean pattern. Therefore, virgin or extra virgin olive oil is the main fat source. If other refined vegetable oils are to be used, they have to be introduced in the tool and substitute of olive oil.

\section{Population test}

In order to verify the usefulness of the tool, food consumption data were collected from a total of ninety participants from different population groups within the framework of 
Table 1 Processed foods with the ingredients used for the estimation of polyphenols

\begin{tabular}{|c|c|c|}
\hline Food & Recipe ingredients & Amount of ingredient \\
\hline Cake & $\begin{array}{l}\text { Refined wheat flour } \\
\text { Virain olive oil }\end{array}$ & $\begin{array}{l}60 \mathrm{~g} \\
7 \mathrm{ml}\end{array}$ \\
\hline Cookies & $\begin{array}{l}\text { Refined wheat flour } \\
\text { Extra virgin olive oil }\end{array}$ & $\begin{array}{l}85 \mathrm{~g} \\
10 \mathrm{ml}\end{array}$ \\
\hline Cookies, chocolate & $\begin{array}{l}\text { Refined wheat flour } \\
\text { Virgin olive oil } \\
\text { Chocolate milk }\end{array}$ & $\begin{array}{l}40 \mathrm{~g} \\
10 \mathrm{ml} \\
25 \mathrm{~g}\end{array}$ \\
\hline Cookies, whole grain & $\begin{array}{l}\text { Buckwheat flour } \\
\text { Whole oat flour }\end{array}$ & $\begin{array}{l}75 \mathrm{mg} \\
10 \mathrm{mg}\end{array}$ \\
\hline Ketchup & $\begin{array}{l}\text { Tomato } \\
\text { White onion } \\
\text { Vinegar } \\
\text { Fresh garlic } \\
\text { Refined olive oil }\end{array}$ & $\begin{array}{l}375 \mathrm{~g} \\
50 \mathrm{~g} \\
5 \mathrm{ml} \\
20 \mathrm{~g} \\
2.5 \mathrm{ml}\end{array}$ \\
\hline Lasagna & $\begin{array}{l}\text { Tomato } \\
\text { White onion } \\
\text { Pasta } \\
\text { Fresh garlic }\end{array}$ & $\begin{array}{l}50 \mathrm{~g} \\
10 \mathrm{~g} \\
35 \mathrm{~g} \\
10 \mathrm{~g}\end{array}$ \\
\hline Margarita pizza & $\begin{array}{l}\text { Tomato } \\
\text { Virgin olive oil } \\
\text { Refined wheat flour } \\
\text { Basil }\end{array}$ & $\begin{array}{l}70 \mathrm{~g} \\
5 \mathrm{ml} \\
40 \mathrm{~g} \\
5 \mathrm{~g}\end{array}$ \\
\hline Mayonnaise & $\begin{array}{l}\text { Extra virgin olive oil } \\
\text { Lemon juice, concentrate } \\
\text { Vinegar }\end{array}$ & $\begin{array}{l}52 \mathrm{ml} \\
8 \mathrm{ml} \\
5 \mathrm{ml}\end{array}$ \\
\hline Potato chips snacks & $\begin{array}{l}\text { Raw potato } \\
\text { Refined olive oil }\end{array}$ & $\begin{array}{l}100 \mathrm{~g} \\
5 \mathrm{ml}\end{array}$ \\
\hline Tomato sauce & $\begin{array}{l}\text { Tomato } \\
\text { Extra virgin olive oil } \\
\text { Fresh garlic } \\
\text { Vinegar } \\
\text { Black pepper } \\
\text { Red pepper } \\
\text { White onion }\end{array}$ & $\begin{array}{l}200 \mathrm{~g} \\
20 \mathrm{ml} \\
20 \mathrm{~g} \\
10 \mathrm{ml} \\
5 \mathrm{~g} \\
65 \mathrm{~g} \\
45 \mathrm{~g}\end{array}$ \\
\hline Vegetable cream & $\begin{array}{l}\text { Zucchini } \\
\text { Virgin olive oil } \\
\text { Carrot } \\
\text { Boiled potato }\end{array}$ & $\begin{array}{l}35 \mathrm{~g} \\
5 \mathrm{ml} \\
35 \mathrm{~g} \\
15 \mathrm{~g}\end{array}$ \\
\hline Vegetable stew & $\begin{array}{l}\text { Green beans } \\
\text { Asparagus } \\
\text { Extra virgin olive oil } \\
\text { Carrot } \\
\text { White onion }\end{array}$ & $\begin{array}{l}40 \mathrm{~g} \\
20 \mathrm{~g} \\
5 \mathrm{ml} \\
25 \mathrm{~g} \\
25 \mathrm{~g}\end{array}$ \\
\hline
\end{tabular}

the European project Stance4Health (https://www. stance 4 health.com). Specifically, thirty adult women, thirty school-age girls and thirty pregnant women participated (September-October 2020). Girls were recruited from two schools in the metropolitan area of Granada with equal socio-economic conditions whose ages ranged from 10 to 11 years. Pregnant women were part of a cohort from the Clinical Hospital of Granada and their ages were between 22 and 35 years. The other thirty women were students in the University of Granada; their ages were between 19 and 28 years. Food intake was recorded for seven consecutive days with the tool, which has a format equivalent to $24 \mathrm{hR}$. The questionnaires were completed with the help of an interviewer trained in nutrition and dietetics. Portion sizes were estimated by the interviewer using food photographs as models. All the data were recorded to guarantee the personal data protection law. The study was approved by the ethics committee of the Universidad de Granada No. 1080/
CEIH/2020 and followed the ethical guidelines of the Declaration of Helsinki. All the participants signed an informed consent before starting the study (in the case of girls, their parents filled the informed questionnaire document).

\section{Data analysis}

Statistical data were analysed with the SPSS 22.0 statistics package. Means and standard deviations were determined for the total daily polyphenol consumption, as well as the weekly intake. The differences between groups were measured by means ANOVA, and a Bonferroni post hoc test was used. The level of significance was established at $P<0 \cdot 05$. The contribution per food group to the daily polyphenol intake was estimated. It was also taken into account if the food was consumed during the week or during the weekend, along with the daily time of the meal. 
Table 2 Mean and standard deviation of total daily polyphenol intake $(\mathrm{mg} / \mathrm{d})$ divided by population group and by distribution in the weekday and weekend $(n 90)$

\begin{tabular}{lcccccccc}
\hline & \multicolumn{2}{c}{ Total week } & & \multicolumn{2}{c}{ Weekday } & & \multicolumn{2}{c}{ Weekend } \\
\cline { 2 - 3 } Population & Mean & SD & & Mean & SD & & Mean & SD \\
\hline Girls & 1541 & 519 & & 1587 & 576 & & 1449 & 889 \\
Adult women & 1766 & 673 & & 1993 & 803 & & 1313 & 472 \\
Pregnant women & 2064 & 631 & & 2346 & 1032 & & 1502 & 269 \\
\hline
\end{tabular}

\section{Results}

Total polyphenol intake of the ninety participants showed an average of $1790 \pm 629 \mathrm{mg} / \mathrm{d}$. If the population is classified according to the three different groups, some differences were found, as shown in Table 2 . The highest polyphenol consumption was observed in pregnant women, with an intake of $2064 \mathrm{mg} / \mathrm{d}$, while in girls the consumption was the lowest with an intake of $1541 \mathrm{mg} / \mathrm{d}$. However, no significant differences were found ( $P>0.05)$ between both groups. Total polyphenol consumption was lower during the weekend in all three population groups compared. Nevertheless, no significant differences were found between weekend and weekdays phenolic intake.

Figure 1 shows the distribution of total polyphenol intake in each of the daily meals. It should be noted that lunch is the meal with the highest intake of polyphenols except in children, where breakfast showed the largest contribution. On the contrary, the food with the lowest contribution was the mid-morning snack.

Figure 2 shows the distribution of total polyphenol intake by food groups. It can be seen how the contribution of each food category to total phenolic intake changes depending on the age. In adult women, most polyphenols are provided by three groups: coffee, cocoa and derivatives, providing about $23 \%$ of total phenolic intake; fruits and derivatives contributing with $18 \%$ and legumes providing another $18 \%$. In girls, coffee, cocoa and derivatives doubled its contribution up to $47 \%$, whereas fruits and derivatives provided $16 \%$ of the total amount of polyphenols, followed by legumes, with $13 \%$. In the case of pregnant women, statistically significant differences $(P<0.05)$ were obtained for several food groups: the contribution of coffee, cocoa and derivatives decreased, being legumes (with 35\%) and fruits and derivatives (with $22 \%$ contribution) the main providers of polyphenols in the pregnant women diet. The following two groups that provided also a significant contribution of polyphenols were vegetables and cereals and derivatives, with $9 \%$ and $8 \%$, respectively.

\section{Discussion}

This paper describes the development of a useful and accurate tool to calculate total polyphenol intake from dietary records. In order to achieve an accurate estimation of polyphenol intake, it is of great importance to consider all the foods ingested. Total phenolic content of foods was gathered from Phenol-Explorer database, since it is the most detailed database and it is also widely used among nutrition professionals ${ }^{(10,20)}$. In most foods, total polyphenol content was obtained via the Folin-Ciocalteu method. Although this is not the best analytical assay to measure total polyphenol content (due to interferences with other substances), these values were used since they can be found for a large amount of foods on PhenolExplorer database. In a previous study, the research group validated a new method to measure the excretion of polyphenols and it was compared with the intake of total polyphenols ${ }^{(21)}$. For this reason, the calculation of total polyphenols intake could be the best way to estimate the total polyphenols of the diet, and not only those from the sum of the families of phenolic compounds, since in many cases it would cause data loss.

Different types of dietary questionnaires are used to estimate polyphenol content ${ }^{(10,20,22)}$. In this sense, the tool was developed on the basis of the $24 \mathrm{hR}$ to obtain more complete nutritional information. Although the use of retention and yield factors should be advisable, it was not possible for all the foods included in the tool due to different reasons: (i) cooking methods are often not recorded in dietary questionnaires and (ii) retention factors for total polyphenols in certain foods are sometimes not reported in the Phenol-Explorer database. For these reasons, we have considered appropriate to use retention factors just for those foods where the cooking method applied is clear and are properly described in the Phenol-Explorer database, as this could otherwise add further confusion errors to the results.

As average, total polyphenol intake measured with the tool was $1790 \pm 629 \mathrm{mg} / \mathrm{d}$, which is in line with other previously published papers. For example, Hoge et al. estimated total polyphenol intake from a FFQ and compared such results with those obtained from a 3-d dietary record. Their results ranged from 1204 to $2271 \mathrm{mg} / \mathrm{d}^{(20)}$. On the other hand, Grosso et al. studied the polyphenol intake of Krakow population (Poland), finding a mean intake of $1756 \pm 695 \mathrm{mg} / \mathrm{d}^{(10)}$. They used Phenol-Explorer as database, whereas food intake records came from FFQ. Polyphenol intake has also been studied in female populations, specifically in several European countries ${ }^{(17)}$. The intake values obtained ranged between 653 and $1552 \mathrm{mg}$ of polyphenols/d, being the Danish population the one with the highest intake. Regarding the Spanish population, it should be highlighted a study where extractable and nonextractable polyphenols were considered ${ }^{(18)}$. This study showed a polyphenol intake higher (2591-3016 mg/d) than those reported by other studies ${ }^{(10,23)}$. Saura-Calixto and Goñi obtained a daily polyphenol intake of $1171 \mathrm{mg}$ for the Spanish population ${ }^{(24)}$. However, in this case, they calculated food consumption via national food consumption databases. 


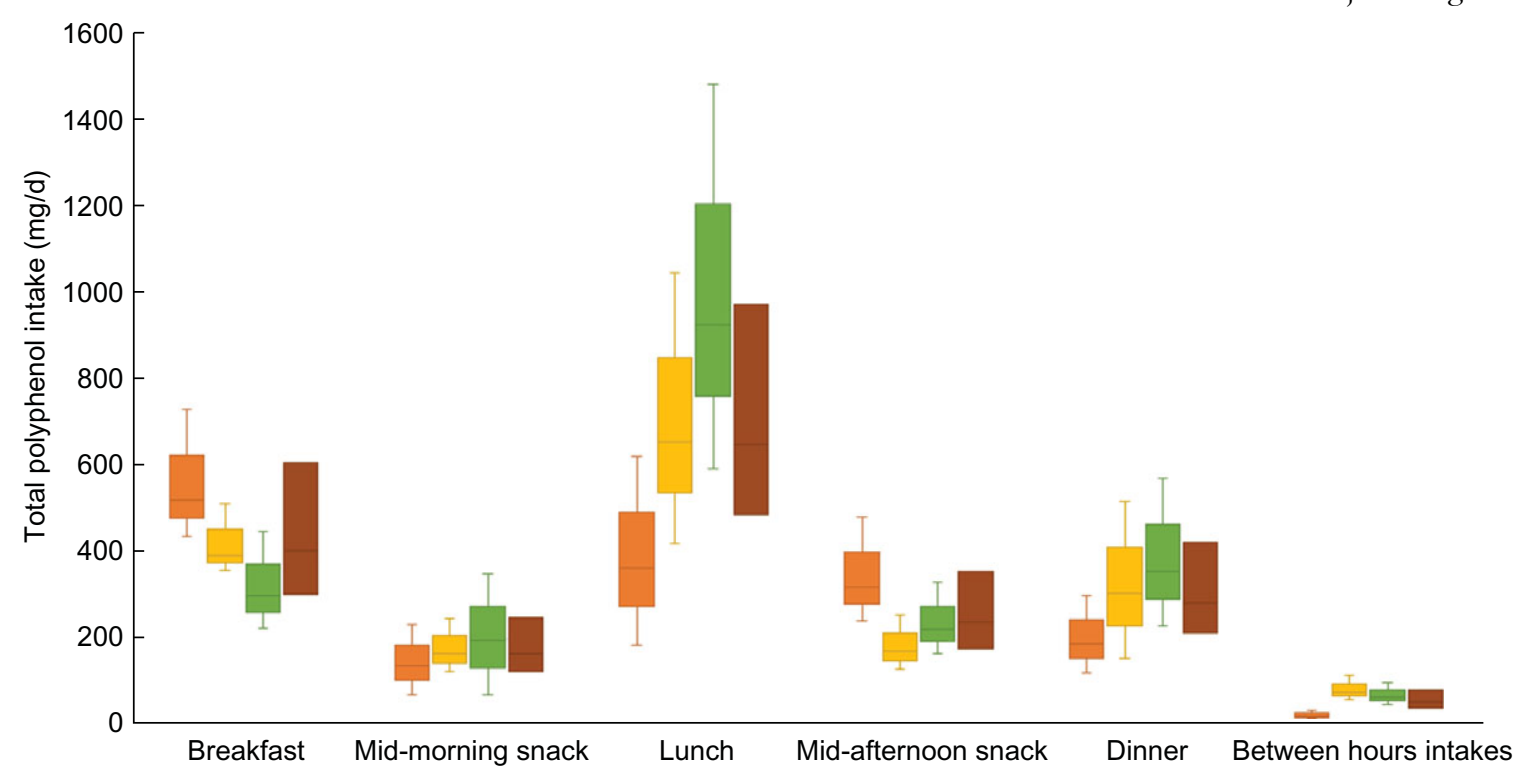

Fig. 1 (colour online) Distribution of the total polyphenol intake $(\mathrm{mg} / \mathrm{d})$ in each of the six daily meals divided by population group: breakfast, mid-morning snack, lunch, mid-afternoon snack, dinner and between hours intakes

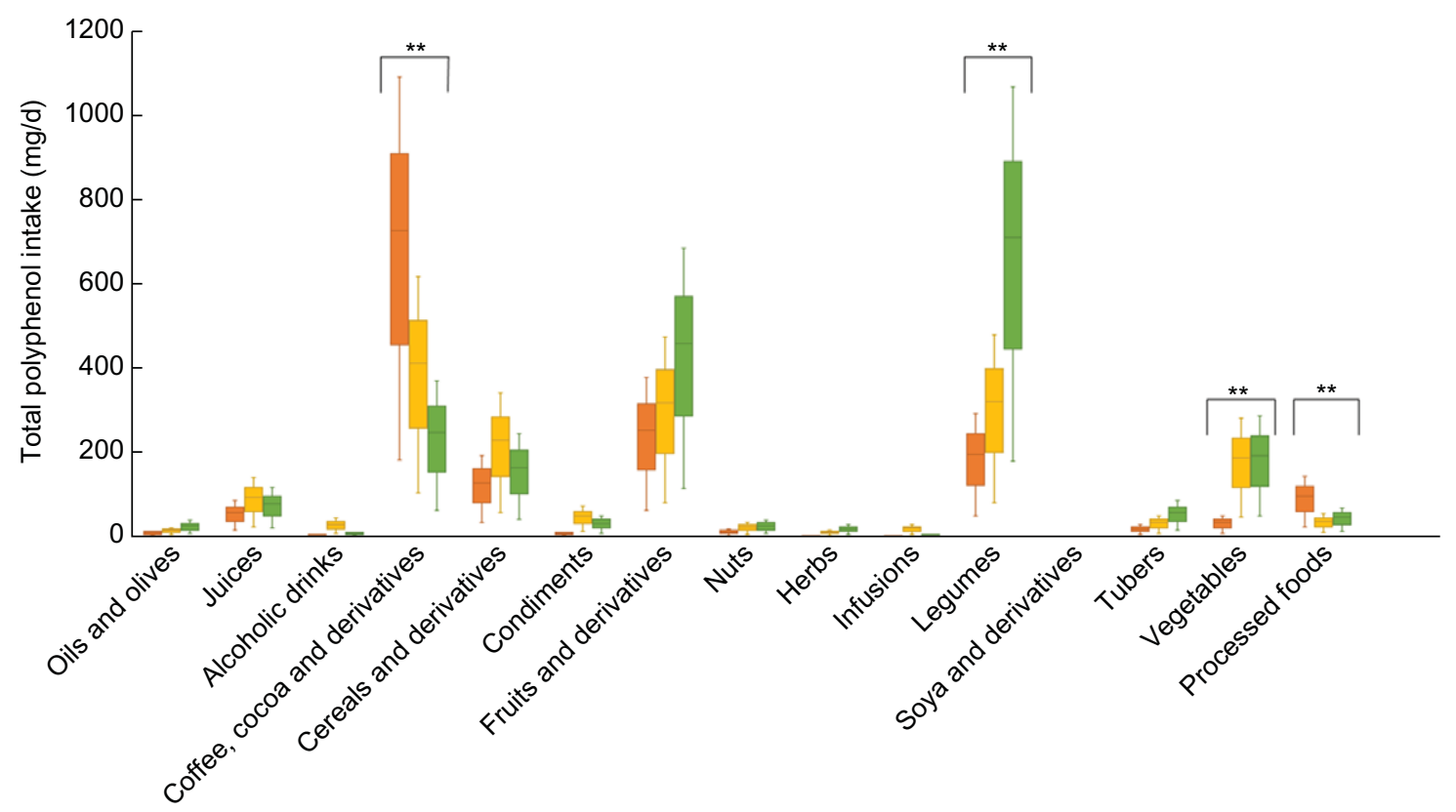

Fig. 2 (colour online) Distribution of the total polyphenol intake $(\mathrm{mg} / \mathrm{d})$ classified into fifteen food groups for each of the three population groups: oils and olives, juices, alcoholic drinks, coffee, cocoa and derivatives, cereals and derivatives, condiments, fruits and derivatives, nuts, herbs, infusions, legumes, soya and derivatives, tubers, vegetables and processed foods. * $S t a t i s t i c a l l y ~ s i g n i f i c a n t$ differences between groups $(P<0.05)$

One of the applications to use the developed tool is the possibility of estimating total polyphenols in different types of populations. There are few studies in children, one of the most important in Europe is the one developed in the HELENA study, that estimated the dietary intake of polyphenols in adolescents ${ }^{(22)}$. However, the results obtained in the HELENA study cannot be compared with those reported in this paper since they used the sum of families of polyphenols, not total polyphenols. Another of the target populations were pregnant women, since there are studies that suggest that a high intake of polyphenols during pregnancy can lead to complications for the fetus ${ }^{(25,26)}$.

In the case of the contribution of different food groups to the daily polyphenols intake, the values found in this study are similar to those reported in other papers: coffee and chocolate, fruits and vegetables were the main contributors of total polyphenols intake ${ }^{(10,27)}$. The consumption of legumes has decreased in the Spanish population in recent 
years $^{(28)}$. Nevertheless, legumes were also an important provider or phenolic compounds, with very similar values to those of fruits and vegetables ${ }^{(29)}$. When we compared the intake of polyphenols during weekends to that of weekdays, it was clear that during the weekend the intake decreased. The reason behind could be a lower intake of legumes, fruits and vegetables during the weekend. Similarly, in other studies, the weekend intake of rye bread, fruits and vegetables were smaller ${ }^{(23)}$ which also resulted in a lower polyphenol intake. Regarding the hours of the meals, the main polyphenol intake was achieved during lunch, meal that usually provides the highest energetic intake. It should be noted that at early ages, the highest intake of polyphenols is obtained at breakfast. This may be due to a high consumption of chocolate and cocoa in the breakfasts of the children ${ }^{(30)}$ and also to the use of different oils to prepare bread toasts ${ }^{(31)}$. In some cases, the food groups may need to be separated in different ways. The tool automatically classifies each food into one of the food groups. However, the tool allows the user to enter foods manually which enables the user to change certain foods to another food group.

The increased need to precisely calculate the intake of total polyphenols from the diet, as is the case of pregnancy, gives importance to having this tool, which would help other researchers to easily obtain reproducible data. An example will be the use of this tool within the European project Stance 4 Health. The tool can be useful for small clinical trials, but it is not useful for large epidemiological studies. For this reason, an APP (an application program that can be downloaded onto a mobile phone to allow a personalised nutrition service) is under development based on the experience of this tool. In addition, the possibility of obtaining individual polyphenols will be introduced. The diet and intake of polyphenols of children and adults from different European countries will be evaluated with these new tools.

\section{Conclusions}

In summary, this tool has demonstrated to be extremely useful to calculate the total polyphenol intake from commonly used dietary records in a simple, fast and accurate way. Results achieved with the tool have been compared to several other studies, reaching always very similar conclusions, aside from the inevitable variations related to dietary records collection. However, the tool has certain limitations: (i) not all foods are included, but in this case, empty slots are available to include new foods at will; and (ii) the tool was built to include all 7 weekdays in the calculations, so that if there is interest in only specific days, calculations between different days would have to be done manually. In view of the results, it can be concluded that the use of this tool could facilitate the estimation of total polyphenol intake in different populations in a precise and reproducible way.

\section{Acknowledgements}

Acknowledgements: This work will be a part of the doctoral thesis of Daniel Hinojosa-Nogueira conducted within the context of the 'Program of Nutrition and Food Sciences' at the University of Granada. The authors also would like to thank Francisco Ríos Jiménez for the help and advice while preparing the tool. Financial support: This work was supported by the European Research Commission (Research Executive Agency) under the research project Stance4Health under Grant (Contract $N^{\circ}$ 816303) and by the 'Plan propio de Investigación y Transferencia' of the University of Granada under the programme 'Intensificación de la Investigación, modalidad B' granted to José A. Rufián-Henares. Conflict of interest: The authors report no conflict of interest. Authorship: The authors responsibilities were as follows: conceptualisation: J.A.R.H. and S.P.C.; methodology: D.H., S.P. and I.G.; tool creation: D.H.; validation: D.H. and S.P.; formal analysis: D.H. and I.G.; writing original draft preparation: D.H. and S.P.; writing review and editing: J.A.R.H. and S.P.C.; project administration: S.P.C.; and funding acquisition: J.A.R.H. All authors read and approved the final manuscript. Ethics of human subject participation: This study was conducted according to the guidelines laid down in the Declaration of Helsinki and all procedures involving research study participants were approved by the Ethics Committee of the University of Granada. Written informed consent was obtained from all participants or from the legally responsible persons.

\section{Supplementary material}

For supplementary material accompanying this paper visit https://doi.org/10.1017/S136898002100183X

\section{References}

1. Willett W (2012) Nutritional Epidemiology, vol. 40. Oxford, UK: Oxford University Press.

2. Ferrer-García JC, Granell Vidal L, Muñoz Izquierdo A et al. (2015) Consumo de frutos secos y aceites vegetables en personas con diabetes mellitus tipo 1 (Consumption of nuts and vegetable oils in patients with type 1 diabetes mellitus). Nutr Hosp 31, 2641-2647.

3. Visioli F, Borsani L \& Galli C (2000) Diet and prevention of coronary heart disease: the potential role of phytochemicals. Cardiovasc Res 47, 419-425.

4. Finicelli M, Squillaro T, Di Cristo F et al. (2018) Metabolic syndrome, Mediterranean diet, and polyphenols: evidence and perspectives. J Cell Physiol 234, 5807-5826.

5. Kardum N \& Glibetic M (2018) Polyphenols and their interactions with other dietary compounds: implications for human health. Adv Food Nutr Res 84, 103-144. 
6. Manach C, Williamson G, Morand C et al. (2005) Bioavailability and bioefficacy of polyphenols in humans. I. Review of 97 bioavailability studies. Am J Clin Nutr $\mathbf{8 1}$, 230S-242S.

7. Probst Y, Guan V \& Kent K (2018) A systematic review of food composition tools used for determining dietary polyphenol intake in estimated intake studies. Food Chem $\mathbf{2 3 8}$, 146-152.

8. Rossi MC, Bassett MN \& Sammán NC (2018) Dietary nutritional profile and phenolic compounds consumption in school children of highlands of Argentine Northwest. Food Chem 238, 111-116.

9. Pinto P \& Santos CN (2017) Worldwide (poly) phenol intake: assessment methods and identified gaps. Eur J Nutr 56, 1393-1408.

10. Grosso G, Stepaniak U, Topor-Mądry R et al. (2014) Estimated dietary intake and major food sources of polyphenols in the Polish arm of the HAPIEE study. Nutrition 30, 1398-1403.

11. Vian I, Zielinsky P, Zilio AM et al. (2015) Development and validation of a food frequency questionnaire for consumption of polyphenol-rich foods in pregnant women. Matern Child Nutr 11, 511-524.

12. Zhang Z-Q, He L-P, Liu Y-H et al. (2014) Association between dietary intake of flavonoid and bone mineral density in middle aged and elderly Chinese women and men. Osteoporos Int 25, 2417-2425.

13. Bhagwat S, Haytowitz DB \& Holden JM (2014) USDA Database for the Flavonoid Content of Selected Foods, Release 3.1. Beltsville, MD, USA: US Department of Agriculture.

14. Neveu V, Perez-Jiménez J, Vos F et al. (2010) PhenolExplorer: an online comprehensive database on polyphenol contents in foods. Database 2010, bap024.

15. Rothwell JA, Urpi-Sarda M, Boto-Ordoñez M et al. (2012) Phenol-Explorer 2.0: a major update of the PhenolExplorer database integrating data on polyphenol metabolism and pharmacokinetics in humans and experimental animals. Database 2012, bas031.

16. Rothwell JA, Perez-Jimenez J, Neveu V et al. (2013) PhenolExplorer 3.0: a major update of the Phenol-Explorer database to incorporate data on the effects of food processing on polyphenol content. Database 2013, bat070.

17. Zamora-Ros R, Cayssials V, Jenab M et al. (2018) Dietary intake of total polyphenol and polyphenol classes and the risk of colorectal cancer in the European Prospective Investigation into Cancer and Nutrition (EPIC) cohort. Eur J Epidemiol 33, 1063-1075.
18. Saura-Calixto F, Serrano J \& Goni I (2007) Intake and bioaccessibility of total polyphenols in a whole diet. Food Chem 101, 492-501.

19. Menal-Puey S \& Marques-Lopes I (2019) Development of criteria for incorporating occasionally consumed foods into a national dietary guideline: a practical approach adapted to the Spanish population. Nutrients 11, 58 .

20. Hoge A, Guillaume M, Donneau A-F et al. (2017) Validation study of a food frequency questionnaire for the measurement of food consumption in polyphenols: use of a urinary bioamarker. Preliminary results. Free Radic Biol Med 108, S40.

21. Hinojosa-Nogueira D, Muros J, Rufián-Henares JA et al. (2017) New method to estimate total polyphenol excretion: comparison of fast Blue BB $v$. Folin-Ciocalteu performance in urine. J Agric Food Chem 65, 4216-4222.

22. Wisnuwardani RW, De Henauw S, Androutsos O et al. (2019) Estimated dietary intake of polyphenols in European adolescents: the HELENA study. Eur J Nutr 58, 2345-2363.

23. Rothausen BW, Matthiessen J, Hoppe C et al. (2012) Differences in Danish children's diet quality on weekdays $v$. weekend days. Public Health Nutr 15, 1653-1660.

24. Saura-Calixto F \& Goñi I (2006) Antioxidant capacity of the Spanish Mediterranean diet. Food Chem 94, 442-447.

25. Zielinsky P \& Busato S (2013) Prenatal effects of maternal consumption of polyphenol-rich foods in late pregnancy upon fetal ductus arteriosus. Birth Defects Res Part C Embryo Today Rev 99, 256-274.

26. Zielinsky P, Piccoli AL Jr, Manica JL et al. (2010) Maternal consumption of polyphenol-rich foods in late pregnancy and fetal ductus arteriosus flow dynamics.J Perinatol 30, 17.

27. Nascimento-Souza MA, de Paiva PG, Pérez-Jiménez J et al. (2018) Estimated dietary intake and major food sources of polyphenols in elderly of Viçosa, Brazil: a population-based study. EurJ Nutr 57, 617-627.

28. Partearroyo T, Samaniego-Vaesken M de L, Ruiz E et al. (2019) Current food consumption amongst the Spanish ANIBES study population. Nutrients 11, 2663.

29. Godos J, Rapisarda G, Marventano S et al. (2017) Association between polyphenol intake and adherence to the Mediterranean diet in Sicily, southern Italy. NFS J 8, 1-7.

30. Ruiz E, Ávila J, Valero T et al. (2018) Breakfast consumption in Spain: patterns, nutrient intake and quality. Findings from the ANIBES study, a study from the international breakfast research initiative. Nutrients $\mathbf{1 0}, 1324$.

31. Marfil R, Giménez R, Martínez O et al. (2011) Determination of polyphenols, tocopherols, and antioxidant capacity in virgin argan oil (Argania spinosa, Skeels). Eur J Lipid Sci Technol 113, 886-893. 